\title{
Are the MADIT II Criteria for ICD Implantation Appropriate for Japanese Patients?
}

\author{
Kaoru Tanno, MD; Fumito Miyoshi, MD; Norikazu Watanabe, MD; Yoshino Minoura, MD; \\ Mitsuharu Kawamura, MD; Syunsho Ryu, MD; Taku Asano, MD; \\ Youichi Kobayashi, MD; Takashi Katagiri, MD
}

\begin{abstract}
Background The Multicenter Automatic Defibrillator Implantation Trial (MADIT) II investigators concluded that prophylactic use of an implantable cardioverter defibrillator (ICD) improved survival in patients with prior myocardial infarction (MI) and reduced the left ventricular ejection fraction (LVEF). However, it is unclear whether MADIT II criteria for ICD implantation are appropriate for Japanese patients.

Methods and Results During the period 1997 to 200190 (M/F: 75/15; mean age: 65 \pm 9 years) of the 3,258 patients who underwent elective cardiac catheterization met MADIT II criteria (Q-wave MI more than 4 weeks prior; LVEF $\leq 0.30$; $>21$ years of age; electrophysiologic testing not required) and were selected in this retrospective study of patient prognosis after catheterization. During the 37 \pm 12 -month follow-up period, 15 patients died of congestive heart failure $(n=9)$, sudden cardiac death $(n=2)$, acute MI $(n=1)$, or noncardiac causes $(n=3)$. The survival rate in the present series was comparable with that in the MADIT II defibrillator group, but higher than that in the MADIT II conventional therapy group. A significantly greater percentage of the present patients were found to be in New York Heart Association class I and have undergone percutaneous coronary intervention than in MADIT II.
\end{abstract}

Conclusion These results suggest that it may be inappropriate to apply MADIT II criteria to Japanese patients. (Circ J 2005; 69: 19-22)

Key Words: Implantable cardioverter defibrillator; Left ventricular dysfunction; Myocardial infarction; Sudden cardiac death

$\mathbf{T}$ he Multicenter Automatic Defibrillator Implantation Trial (MADIT) II revealed that prophylactic use of an implantable cardioverter defibrillator (ICD) improved the prognosis of patients with left ventricular (LV) dysfunction and no history of ventricular tachyarrhythmia after myocardial infarction (MI)! The prognosis of patients with LV dysfunction after MI is poor even in Japan, 2,3 although treatment strategies have greatly reduced the number of post-MI cardiac events in recent years. However, because it is not clear whether prophylactic ICD use would improve the prognosis of Japanese patients with LV dysfunction, we conducted a retrospective study to clarify the prognosis of MADIT II-like Japanese patients who did not undergo ICD implantation.

\section{Methods}

The MADIT II criteria for ICD implantation are as follows: Q-wave MI $>4$ weeks prior, $\mathrm{LV}$ ejection fraction $($ LVEF $)<30 \%$ and age $>21$ years. Nonsustained ventricular tachycardia and electrophysiologic testing are not part of the eligibility criteria. Among 3,258 patients who underwent cardiac catheterization at Showa University Hospital during the period 1997 to 2001, 90 met the MADIT II crite-

(Received June 4, 2004; revised manuscript received September 24, 2004; accepted October 7, 2004)

Third Department of Internal Medicine, Showa University School of Medicine, Tokyo, Japan

Mailing address: Kaoru Tanno, MD, Third Department of Internal Medicine, Showa University, 1-5-8 Hatanodai, Shinagawa-ku, Tokyo

142-8666, Japan. E-mail: k-tanno@p02.itscom.net ria and were included in this study. There were 75 men and 15 women, with an average age of $65 \pm 9$ years. The date of cardiac catheterization was regarded as day 1 of the study. The follow-up period lasted until either patient death or March 2003. The survival rate, cause of death, and clinical characteristics of these patients were examined and compared with those of the MADIT II patients.

All data measured are shown as average \pm standard deviation. ANOVA or $\chi^{2}$ test was used to analyze differences when there were more than 2 groups; unpaired t-test or $X^{2}$ test was used for comparison between nonsurvivors and survivors. $\mathrm{P}<0.05$ was considered to be statistically significant.

\section{Results}

Outcome

During the follow-up period of $37 \pm 12$ months, 15 $(16.7 \%)$ of the 90 patients died of congestive heart failure $(n=9)$, sudden cardiac death $(n=2)$, acute MI $(n=1)$, or noncardiac causes $(n=3)$. Four patients had sustained ventricular tachycardia (VT) during the follow-up period. None of them had a history of cardiopulmonary arrest and 3 underwent ICD implantation after documentation of sustained VT. They were the only patients who underwent ICD implantation in this group of 90 patients. The fourth patient died of noncardiac disease before ICD implantation.

\section{Comparison With MADIT II}

Analysis of the Kaplan-Meier curves plotted with data from our study and from MADIT II (Fig 1) indicated a 


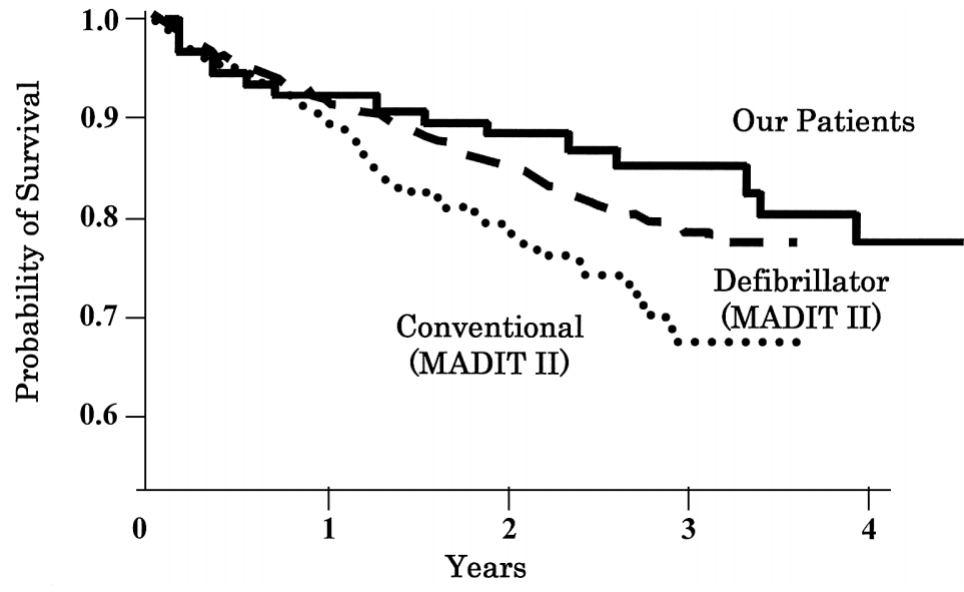

Fig 1. Probability of survival. Event-free survival, depicted by Kaplan-Meier curves, of patients in our series (solid line) and patients in the MADIT II study who underwent conventional therapy (dotted line) and defibrillator implantation (dashed line).

Table 1 Patient Characteristics

\begin{tabular}{lccc}
\hline \hline & \multicolumn{3}{c}{ MADIT II } \\
\cline { 2 - 4 } & $\begin{array}{c}\text { Present series } \\
(n=90)\end{array}$ & $\begin{array}{c}\text { Defibrillator } \\
(n=742)\end{array}$ & $\begin{array}{c}\text { Conventional therapy } \\
(n=490)\end{array}$ \\
\hline Age (years) & $64 \pm 10$ & $64 \pm 10$ & $65 \pm 10$ \\
Male sex (\%) & 80 & 84 & 85 \\
NYHA functional class & $79 *$ & 35 & 39 \\
I & 18 & 35 & 34 \\
II & 3 & 25 & 23 \\
III & & 5 & 4 \\
IV & 73 & 53 & 53 \\
Hypertension (\%) & 37 & 33 & 38 \\
Diabetes $(\%)$ & $10^{*}$ & 58 & 56 \\
Coronary bypass surgery (\%) & $77^{*}$ & 45 & 42 \\
Percutaneous coronary intervention $(\%)$ & 78 & 88 & 87 \\
Acute myocardial infarction $>6$ months $(\%)$ & & & \\
\hline
\end{tabular}

NYHA, New York Heart Association. ${ }^{*} p<0.05$ derived from $\mathrm{x}^{2}$ test.

Table 2 Electrocardiographic Findings

\begin{tabular}{lccc}
\hline \hline & \multicolumn{3}{c}{ MADIT II } \\
\cline { 2 - 4 } & Present series & Defibrillator & Conventional therapy \\
\hline Atrial fibrillation $(\%)$ & 5 & 9 & 8 \\
QRS $>$ 0.12(\%) & $21^{*}$ & 50 & 51 \\
Nonspecific conduction defect & 9 & 22 & 26 \\
Right bundle branch block & 9 & 9 & 7 \\
Left bundle branch block & 3 & 19 & 18 \\
LVEF $(\%)$ & $24 \pm 4$ & $23 \pm 5$ & $23 \pm 6$ \\
\hline
\end{tabular}

$L V E F$, left ventricular ejection fraction. ${ }^{*} p<0.05$ derived from $\mathrm{\chi}^{2}$ test.

higher event-free survival rate in our patients than in MADIT II patients at 3 years after enrollment. The survival rate in our series was comparable with that in the defibrillator group of the MADIT II study, but higher than that in the conventional therapy group of the MADIT II study. Therefore, we compared the characteristics of our patients with those of these 2 MADIT II groups (Table 1). Compared with MADIT II, a significantly greater percentage of the present patients were found to be in New York Heart Association (NYHA) functional class I and to have undergone percutaneous coronary intervention (PCI) and a significantly lower percentage had undergone coronary artery bypass grafting. In addition, a significantly higher prevalence of a QRS width of more than $0.12 \mathrm{~s}$ was observed in the MADIT II patients (Table 2 ). There was a significantly greater percentage of patients taking a $\beta$-blocker, digitalis, or lipid- lowering statin drug in the MADIT II study than in our series, but there was a significantly greater percentage of patients taking a Ca-antagonist in our series (Fig 2).

\section{Survivors vs Nonsurvivors}

We noted 2 significant differences between survivors and nonsurvivors in our series (Table 3): the nonsurvivors were older and had a higher NYHA functional status. None of the other factors, including the electrocardiographic findings (Table 3 ), differed significantly between survivors and nonsurvivors.

\section{Sudden Death}

Two patients died suddenly during the follow-up period. One died during the night and could not be revived by the ambulance officers when they were called in the morning; 
(\%)

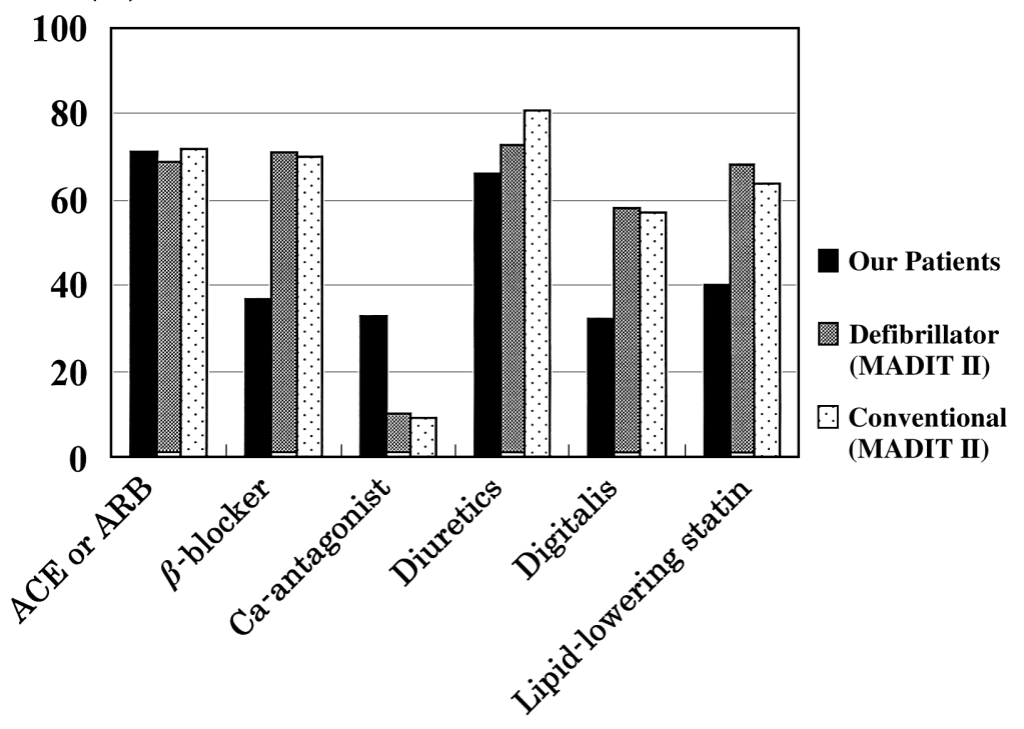

Fig 2. Medical treatments. There was a significantly greater percentage of patients taking a $\beta$-blocker, digitalis, or lipid-lowering statin drug in the MADIT II study than in our series, but there was a significantly greater percentage of patients taking a Ca-antagonist in our series than in the MADIT II study. ACE, angiotensin-converting enzyme inhibitor; $\mathrm{ARB}$, angiotensin II receptor blocker.

Table 3 Characteristics of Nonsurvivors and Survivors in the Present Series

\begin{tabular}{|c|c|c|c|}
\hline & $\begin{array}{c}\text { Nonsurvivors } \\
(n=15)\end{array}$ & $\begin{array}{c}\text { Survivors } \\
(n=75)\end{array}$ & $p$ value \\
\hline Age (years) & $69 \pm 8.1$ & $63 \pm 10$ & $<0.05$ \\
\hline$M / F$ & $12 / 3$ & $60 / 15$ & $N S$ \\
\hline \multicolumn{4}{|l|}{ NYHA functional class } \\
\hline$I$ & 5 & 65 & $<0.05$ \\
\hline II & 7 & 10 & \\
\hline III & 3 & 0 & \\
\hline Hypertension & 9 & 56 & $N S$ \\
\hline Diabetes & 7 & 26 & $N S$ \\
\hline Coronary bypass surgery & 3 & 6 & $N S$ \\
\hline Percutaneous coronary intervention & 9 & 59 & $N S$ \\
\hline Acute myocardial infarction $>6$ months & 10 & 61 & $N S$ \\
\hline \multicolumn{4}{|l|}{ ECG findings* } \\
\hline$R R$ & $0.781 \pm 0.102$ & $0.819 \pm 0.147$ & \\
\hline$P R$ & $0.175 \pm 0.026$ & $0.170 \pm 0.042$ & \\
\hline$Q R S$ & $0.122 \pm 0.038$ & $0.110 \pm 0.024$ & \\
\hline$Q T$ & $0.390 \pm 0.048$ & $0.386 \pm 0.041$ & \\
\hline$Q T c$ & $0.442 \pm 0.045$ & $0.429 \pm 0.032$ & \\
\hline$Q T d$ & $94 \pm 24$ & $85 \pm 28$ & \\
\hline QTcd & $103 \pm 26$ & $95 \pm 32$ & \\
\hline
\end{tabular}

NYHA, New York Heart Association. $p$ values derived from unpaired t-test or $\mathrm{X}^{2}$ test.

*Differences were not statistically significant.

the other patient felt chest discomfort during a daytime meeting and then lost consciousness. His colleagues started cardiopulmonary resuscitation and upon arrival at the emergency room, the first electrocardiogram showed sinus rhythm and pulseless electrical activity. However, despite emergency PCI and cardiopulmonary support by intraaortic balloon pumping and mechanical ventilation, he died several hours later.

\section{Discussion}

The survival rate of the present patients who met the MADIT II criteria was comparable or superior to that of the MADIT II patients. Heart failure was the most frequent cause of death. The prognosis of patients with MI is improving with the increasing use of aggressive coronary revascularization and administration of angiotensin-converting enzyme inhibitor (ACEI), angiotensin II receptor blocker (ARB), or $\beta$-blocker2,4-6 Although the medical therapy of the present patients was comparable or inferior to that in MADIT II, a significantly greater percentage of them underwent PCI than in MADIT II. Furthermore, 60\% of the patients underwent primary PCI at the onset of AMI, which may account for the improved survival rate of our patients?-9 Primarily, event rates of AMI and coronary death are very low in Japan ${ }^{10}$ compared with other industrialized nations reported in the WHO-MONICA project!1 Aggressive therapy that includes primary PCI, ACEI, ARB or $\beta$-blocker can prevent LV remodeling, preserve LV function and keep the QRS width short ${ }^{2,4,6,9}$ and these factors may be associated with a greater percentage of patients in NYHA class 1 , which may be related to the improved outcomes in this series.

There was a significantly fewer percentage of patients with a wide QRS compared with MADIT II, which may be related to the better outcomes of the present patients. How- 
ever, there was no significant difference in the QRS width between survivors and nonsurvivors, probably because of the small number of patients with a wide QRS: 5 of 19 patients with a wide QRS died compared with 10 of 71 patients with a narrow QRS who died. The total mortality of patients with a wide QRS was higher than that of patients with a narrow QRS, but was not statistically significant $(\mathrm{p}=0.178)$.

Two patients died suddenly during the follow-up period. Could an ICD have saved their lives? One patient showed sinus rhythm and electromechanical dissociation after cardiac arrest, which cannot be reversed with an ICD. Although we agree that the ICD is currently the most effective and reliable method of preventing sudden cardiac death, it is not effective in all cases $!^{2}$ Studies of automated external defibrillators revealed that ventricular fibrillation occurred in $44-71 \%$ of patients who suffered cardiac arrest ${ }^{13,14}$ The incidence of sudden cardiac death by any cause other than ventricular fibrillation increases in patients with low cardiac function! ${ }^{15,16}$ An ICD is effective for terminating ventricular tachyarrhythmias and restore sinus rhythm, but it is not useful for pulseless electrical activity! ${ }^{12}$ Therefore, we should not place too much confidence in the ICD.

Ventricular tachycardia occurred in 4 patients, 3 of whom subsequently underwent ICD implantation. Twenty-two patients in the conventional therapy group in the MADIT II study underwent ICD implantation during the trial, 21 for documented or suspected malignant ventricular arrhythmias and 1 at the physician's discretion. Ventricular tachyarrhythmias do not always lead to sudden cardiac death and the types of patients likely to benefit most from ICD implantation needs to be clarified ${ }^{17,18}$

\section{Conclusion}

There were more positive outcomes in the MADIT IIlike patients in our series than in the MADIT II patients. Only 2 of 90 MADIT II-like patients died suddenly, 1 of whom might have been saved by an ICD. Thus, it may be inappropriate to apply MADIT II criteria for ICD implantation to Japanese patients.

\section{References}

1. Moss AJ, Zareba W, Hall WJ, Klein H, Wilber DJ, Cannom DS, et al. Prophylactic implantation of a defibrillator in patients with myocardial infarction and reduced ejection fraction. N Engl J Med 2002; 346: $877-883$.

2. Ishikawa K, Kimura A, Taniwa T, Takenaka T, Hayashi T,
Kanamasa K. Modification of treatment strategies over a period of 14 years has markedly reduced cardiac events among post-myocardial infarction patients. Circ J 2002; 66: 881-885.

3. Ohno J, Watanabe E, Toyama J, Kawamura T, Ohno M, Kodama I. Risk stratification and survival in post myocardial infarction patients: A large prospective and multicenter study in Japan. Int J Cardiol 2004; 93: 263-268.

4. Domanski MJ, Exner DV, Borkowf CB, Geller NL, Rosenberg Y, Pfeffer MA. Effect of angiotensin converting enzyme inhibition on sudden cardiac death in patients following acute myocardial infarction: A meta-analysis of randomized clinical trials. $J$ Am Coll Cardiol 1999; 33: 598-604.

5. The-CAPRICORN-investigators. Effect of carvedilol on outcome after myocardial infarction in patients with left-ventricular dysfunction. Lancet 2001; 357: 1385-1390.

6. Ishikawa K, Miyataka M, Kimura A, Takeda N, Hirano Y, Hayashi $\mathrm{T}$, et al. Beta-blockers prevent cardiac events in Japanese patients with myocardial infarction. Circ J 2004; 68: 59-67.

7. Zijlstra F, Hoorntje JCA, de Bore MJ, Reiffers S, Miedema K, Ottervanger JP, et al. Long-term benefit of primary angioplasty as compared with thrombolytic therapy for acute myocardial infarction. N Engl J Med 1999; 341: 1413-1419.

8. Igarashi Y, Aizawa Y, Satoh T, Konno T, Ojima K, Aizawa Y. Predictors of adverse long-term outcome in acute myocardial infarction patients undergoing primary percutaneous transluminal coronary angioplasty. Circ J 2003; 67: 605-611.

9. Keeley EC, Boura JA, Grines CL. Primary angioplasty versus intravenous thrombolytic therapy for acute myocardial infarction: A quantative review of 23 randomised trials. Lancet 2003; 361: 13-20.

10. Tanabe N, Saito R, Sato T, Hayashi S, Toyoshima H, Seki N, et al. Event rates of acute myocardial infarction and coronary deaths in Niigata and Nagaoka cities in Japan. Circ J 2003; 67: 40-45.

11. Tunstall-Pedoe H, Kuuiasmaa K, Amouyel P, Arveiler D, Rajakangas AM, Pajak A. Myocardial infarction and coronary deaths in the World Health Organization MONICA project: Registration procedure, event rates, and case-fatality rates in 38 populations from 21 countries in four continents. Circulation 1994; 90: 583-612.

12. Mitchell LB, Pineda EA, Titus JL, Bartosch PM, Benditt DG. Sudden death in patients with implantable cardioverter defibrillators. J Am Coll Cardiol 2002; 39: 1323-1328.

13. Page RL, Joglar JA, Kowal RC, Zagrodzky JD, Nelson LL, Ramaswamy K, et al. Use of automated external defibrillators by a U.S. airline. N Engl J Med 2000; 343: 1210-1216.

14. Valenzuela TD, Roe DJ, Nichol G, Clark LL, Spaite DW, Hardman RG. Outcomes of rapid defibrillation by security officers after cardiac arrest in casinos. N Engl J Med 2000; 343: 1206-1209.

15. Parish DC, Dinesh Chandra KM, Dane FC. Success changes the problem: Why ventricular fibrillation is declining, why pulseless electrical activity is emerging, and what to do about it. Resuscitation 2003; 58: 31-35.

16. Peberdy MA, Kaye W, Ornato JP, Larkin GL, Nadkarni V, Mancini ME, et al. Cardiopulmonary resuscitation of adults in the hospital: A report of 14720 cardiac arrests from the National Registry of Cardiopulmonary Resuscitation. Resuscitation 2003; 58: 297-308.

17. Hohnloser SH, Ikeda T, Bloomfield DM, Dabbous OH, Cohen RJ. Twave alternans negative coronary patients with low ejection and benefit from defibrillator implantation. Lancet 2003; 362: 125-126.

18. Wilber DJ, Zareba W, Hall WJ, Brown MW, Lin AC, Andrews ML, et al. Time dependence of mortality risk and defibrillator benefit after myocardial infarction. Circulation 2004; 109: 1082-1084. 